\title{
INFORMATION SYSTEMS FOR BUSINESS PLANNING
}

\author{
Sasho Kozuharov, Natasha Ristovska \\ University of Tourism and Management - Skopje, Macedonia
}

\begin{abstract}
:
This The aim of this paper is to analyze the information systems as integrated systems of man and machine for providing support for the operations, the management and the decision making function in the organization. The integration of business planning and information systems is considered as an important factor of doing successful business and gaining competitive advantage in the changing world. Business planning software is developing during these recent years according to the growing needs of users and enterprises to adjust to the dynamic environment and to innovate and advance their business activities. They are a significant instrument for the quality of the strategic planning process.

The differences between the traditional and modern systems of planning are elaborated in the paper. The problems of the planning process that is managed traditionally are emphasized. The main concentration is given on the numerous innovations, the use of information technology and the new trends in software, programs and systems that have changed the way enterprises carry out and control the planning process.
\end{abstract}

\section{Key words:}

information systems, business planning, decision making. software.

\section{INTRODUCTION}

The information is merging all business functions and provides the basis for all managerial decisions. It is the cornerstone of all enterprises and represents a source of competitive advantage. The aim of management information system is to improve the performance of an enterprise by improving the quality of managerial decision. The benefits of an effective information system are: an improved understanding of the business functions, improved communications, prompted decision making, better problem analysis and better control. As a business becomes more complex, decentralized and globally dispersed, the importance of the function of information systems dramatically increases.

Efficient information systems are similar to a library that collects, categorizes and archives the data that is used by all levels of management in the enterprise. The enterprises without corresponding information systems are losing their competing position on the market. On the other hand, the dispose of information provides the business with different competencies. For example, low cost production and good customer service can depend on solid information system.

\section{TRADITIONAL AND MODERN PLANNING SYSTEMS}

The basic problem tied to business planning grows out from the fact that the planning process is not adapted to the changes occurring in the business environment. Enterprises are still using traditional business planning methods and tools which cannot support the new demands of the environment. Possible problems related to business planning that occur in enterprises are related to ${ }^{1}$ :

- Planning cycles that are too long, meanwhile the environment is changing and significantly affects the plan, so these changes are not taken into account.

- Top - down planning, when few people make decisions for subordinates, with insufficient information about the real condition of lower levels of management in the hierarchy, which cracks the link between top management and the lowest level of management.

- There is no direct link between individual and the overall objective of the enterprise - managers at dif-

$\overline{1}$ Buble, M. (2000), Management, Ekonomsku fakultet Split, Split, p. 58 
ferent levels are not cooperating enough in order to align plans, making conflict situations to occur.

- Disconnection between the units - there is not enough strong relationship between departments, each department uses its own information for itself, and the enterprise is losing the effect of the synergy that can be used. This is most apparent in the preparation of reports. Often already existing statements are made twice, not all departments are familiar with it, because of lack of connectivity and lack of communication.

- Planning is conceived on studying many charts that could clearly help in identifying trends and enabling faster decision making. Due to the large amount of information, planning is too much focused on data gathering, instead of their analysis.

These problems make the planning process harder and slower because enterprises manage their operations traditionally, concentrating on past results. This way is not appropriate, because things cannot be changed after they occur, so enterprises need to plan in time or carry out continuous planning.

The modern planning system needs to be adapted to today's business conditions and should possess the following characteristics:

- Continuous planning - including current forecasts and weekly plans for each department. Unlike traditional planning, which contains one or two cycles of annual budgeting, current forecasts are made for the next three months. Along with current forecasts, weekly plans are used for individual departments that are attached to each other. It starts with marketing and sales, and after the consolidation of these two plans, the production and purchase plan are developed. That is the basic cycle that can be upgraded. The application of flexible ways of managing, monitoring and enforcement of current plans, can allow dynamic changes.

- Inclusion of all decision makers in business planning - modern planning process should include managers from all levels in the enterprise. Planning thus can be implemented faster and easier. When users have easy access to information, can carry out quality decisions.

- Linking business strategy with operational objectives - in most enterprises, managers at higher levels are those who conduct the strategic planning process. It is important for the survival of the company, but is useless if parts of that business strategy cannot be implemented at the operational level. The enterprise should function in a way that the objectives of all levels will be focused on achieving the corporate objectives. To achieve this, the enterprise needs to realize continuous communication and cooperation at all organizational levels.

- Connecting all the departments in the enterprise ensuring that all developments that occur in a particular department can affect the goals of other departments. This means that integration is achieved in the planning processes and the result is a completely coordinated enterprise that can cope with the market requirements, competitive pressures and can quickly restructure and adapt to the new market situation.

- Planning should have solid information base - to develop a coordinated enterprise with well-established plans that include millions of information that are used from thousands of people at the same time.

These features accelerate and facilitate the planning process. Less time is spent on data collection, their treatment and other non-productive activities, and more time is used for the analysis. It brings great benefit to the enterprise, since the bases of the analysis are good decisions that will guide the further activities towards greater profits.

\section{SOFTWARE FOR BUSINESS PLANNING}

Before Today, successful planning cannot be conducted without the appropriate software. The last three decades have occurred numerous innovations that have changed the way enterprises carry out and control the planning process. This software over time adapts to the needs of users. The chronological display of innovation development starts in ${ }^{3}$ :

1970s -systems that support decision making - managers use them to solve complex, unstructured tasks that cannot be solved in a standard way. They enable enterprises to model the future. Databases are used for collection of information, where data are presented in a simple and understandable way to managers. Such planning allows identifying the problems on the market and creating the strategies.

1980s - Executive Information Systems - which allow managers to examine organizational strengths and weaknesses, without the help of programmers. Computer technology is used to display data in a common format that ensures quick and easy access to information. Each system is tailored to the needs and desires of the individual user and the information is presented in an understandable way.

1990s - Business Intelligence - is a set of methodologies and processes, such as extraction, transformation and aggregation, which helps to convert the data into useful information. This information may have different ways to visualize and present, and are used for reporting, analysis, forecasting and supporting business decision making ${ }^{4}$. Business intelligence has become a key factor to accelerate the process of planning, reporting and analysis. Using methodologies such as data warehousing, data mining and data structures for quick analysis, business intelligence helps to transform data into information and their visual presentation to final users. On the basis of such information, the users can easily understand the enterprise's operations and the business environment in order to easily make decisions.

3 Ibid., p.62

4 Oreščanin, D. (2007), Čemu zapravo služi Business Intelligence?, www.inteligencija.com. (20.03.2014) 
These innovations have resulted in increased availability of information to final users, contributing to accelerate transaction processes and partly to facilitate decision making. None of these innovations does sufficiently assist in the planning process or to the top management. There is still a need for a system that will help the top management in implementing the established business strategies and for effective decision making. Today there is a good solution to these problems which began seriously to be applied, the corporate performance management ${ }^{5}$.

The effort to abandon traditional planning and embrace new trends in planning resulted in a new discipline called corporate performance management. It includes the methodologies, metrics, processes and systems used to monitor and manage the business performance of the enterprise. Corporate performance management consists of a set of management and analytic processes, supported by technology, that enable the business to define strategic goals and then manage and measure performance consistent with those goals. The basic process of corporate performance management includes financial planning, operational planning, business modeling, consolidation and reporting, analysis and control of key performance indicators linked to strategy ${ }^{6}$.

Corporate performance management integrates these processes into a single continuous process. It is very helpful in formulating a management strategy. It helps the holders of the budget to provide money, people and resources that are necessary to achieve corporate strategic goals. It also includes forecasting techniques that allow analysis of trends and forecast future performance. It also allows users to create their own reports using business intelligence. It converts data into understandable reports on the basis of which analyses are performed and decisions are made. Today's business intelligence tools allow users to independently ask questions and create reports without the need of technical experts, which further speeds up the planning process.

Corporate performance management involves consolidation of data from various sources, searching and analyzing data and implementing the results in practice ${ }^{7}$. The basic logic of corporate performance management is very simple. This system allows closing the circle that begins with determining the current position of the company and the direction of movement. This is followed by setting the objectives and allocation of available resources in a way that the desired goals will be easily reached. Objectives can be modified in compliance with the changes in the business environment. After the performance objectives are achieved, the results are compared to with those that are planned. On that basis, reports are made and analysis is conducted. Through analysis the reasons for possible deviations are determined and the relation between costs and benefits. This analysis is the basis for formulating new business strategies. Closing the circle means that every-

5 Geishecker, L. and Rayner, N. (2001), Corporate Performance Management: BI Collides with ERP, Gartner Inc., Stamford, p. 81

6 Rayner, N., Buytendijk, F. and Geishecker, L. (2002), The Processes That Drive CPM, Gartner Inc., Stamford, p. 62

7 Frolick, M.N. and Ariyachandra, T.R. (2006), "Business performance management: one truth", Information system management Journal, Vol. 23, No.1, pp. 41-48 one in the company can make decisions based on quality information and to take appropriate actions in order to achieve the strategic goals of the enterprise. The result is a system that brings together all the processes needed for quality performance of the enterprise.

In order for corporate performance management to be implemented in the enterprise, there is a need of an appropriate software foundation. As a basis for corporate planning, Cognos offers a solution called Cognos Enterprise Planning Series. It integrates all processes that are important for corporate performance management: planning, budgeting, forecasting, consolidation, reporting and analysis. The software consists of three elements ${ }^{8}$ :

- Cognos Planning Analyst- which allows creating, comparing and developing business scenarios and assumptions.

- Cognos Planning Contributor - allows participation in the planning process of all stakeholders employees, suppliers, customers.

- Cognos Planning Consolidation - enables the preparation of reports and analysis.

Analyst (Cognos Planning Analyst) ${ }^{9}$ is a system for business planning and forecasting. Financial experts apply this system to define business processes. It enables display of organizational structure and data flow in the enterprise and their interconnection. It enables reduction the planning and budgeting cycle, because it simplifies the data manipulation and display of data facilitates their understanding. It also allows easy adjustment to changes in the environment, such as the addition of new products, plants or cost centers. Some systems that support strategic decisions are too sophisticated, expensive and difficult to use by different levels of managers in the enterprise. However, strategic planning software ${ }^{10}$ should be simple. Simplicity enables broad adoption by managers because their involvement is essential for effective planning.

A software product for strategic planning that provides managers and executives a simple and an effective approach for developing organizational strategies is CheckMATE. This PC software performs analysis of planning generates potential strategies. It incorporates the most modern techniques of strategic planning. Users do not need any previous experience with computers or knowledge of strategic planning. This software promotes communication, understanding, creativity and progressive thinking of the users. CheckMATE is not a database; it is a specialized system that guides the enterprise through the formulation and implementation of strategy. The main advantage of the new 2002 version of this software is its simplicity and participatory approach. The user is asked appropriate questions, the answers are recorded, information is assimilated, and the results are printed. Individuals can work independently with the software, and then

8 http://www-01.ibm.com/software/analytics/cognos/planning/ (19.03.2014)

9 Bidgoli, H. (2004), The Internet Encyclopedia, Vol. 1, John Wiley \& Sons Inc, New York, p. 707

10 Khosrow-Puor, M. (2006), Emerging Trends and Challenges in Information Technology Management, Idea Group Inc, Stratford, p. 865 
the program will develop joint recommendations for the enterprise.

Closed and open software programs are developed in a way that enables the user to input the necessary information and to get appropriate analysis and possible solutions that can serve to the top management as a support for their strategic analysis, making strategic choice and coping with strategic changes and strategic implementations, i.e. strategic management. Along with the increasing complexity and turbulence in the business environment and the development of the information technology, information systems are developed to support strategic decision making. Robert J. Mockler classifies the of strategic management software in several groups ${ }^{11}$ :

- Commercially available conventional computer software to support strategic decision making, Conventional computer software with general purpose and systems used for strategic planning,

- Systems that are based on knowledge to support strategic management,

- Integral - group software for strategic management, and

- Strategic use of computer - information systems.

The development of decision support system-DSS began at the end of the 70's and in the 80 's but the 90 's were marked by the development of numerous industrial software packages to support decision making. Within the conventional software designed as special support for strategic decision making, programs that deserve special attention are: ANSPLAN-A, Strategic Planning Computer model - SPC, BASICS PC and SUCCES.

ANSPLAN-A is a program specifically designed for strategic analysis in a turbulent environment. It is useful in cases where there is discontinuity, in turbulent industries like computer software industry, where there are surprises and unexpected situation in everyday activities. The computer model of strategic planning is used together with standard spreadsheet packages such as Lotus, Excel, etc. It is used to develop enterprises' strategic plans. Input data are: basic information about the enterprise, its branch and competition. The process of working with this software model has three parts: market data analysis, writing a report on the enterprise's mission, opportunities and threats, a detailed listing of the assumptions for the next five years, including trends in the industry; combining the information gathered and providing recommendations for the future strategy, graphically presenting the past and the future position of the enterprise over the competition, as well as the position of the branch as a whole.

BASICS PC is software that generates the preparation of forecasting scenarios and strategic planning. It provides a combination of group and expert opinion, analysis of trends and cross- analysis of long-term forecasting, analysis of multiple factors in highly uncertain conditions. Initially, the user is defining the area for prediction and determines the factors that affect or indicators that are measured or described. The user for each factor should determine domain value and probability. BASICS PC is

11 Buble, M. (2000), Management, Ekonomsku fakultet Split, Split, p. 59 equipped with a matrix of interdependence and allows calculating all cross values. On those grounds different variants of strategic plans can be considered

SUCCESS is a software package for business policy and strategy. It is used to analyze the opportunities and threats, exploring strategic change and identification and evaluation of possible alternatives for enterprise's development. The selection of each strategy affects specific values of certain key factors, such as technological progress, product innovation, size of business units, growth rate, etc.

According to R. J Mockler, conventional software for general purpose and systems that are used in strategic planning are ${ }^{12}$ : Database Systems, Financial analysis and reporting systems, Financial Planning Simulation and modeling, Statistical analysis and econometric software, Decision matrix software, Pairwise comparison, Decision trees, Linear programming, Risk assessment, Creativity enhancement, and Executive information systems.

The integrated group software for strategic management despite advanced forms of commercial software includes experimental intelligent systems and systems for group decision making support. The most developed form of software for strategic use is strategic intelligent system that enables computers to mimic human intellect. Artificial intelligence is the discipline that deals with the development of commercial products. The business intelligence has different components: databases, executive information systems, systems for decision support, online analytical data processing and implementation of the strategy through the use of BSC method.

\section{CONCLUSION}

Business planning is a systematic way to connect the enterprise with the future. It is an attempt to link the effects of external factors that can be controlled, strengths and weaknesses, with goals and guidelines in order to achieve the desired result. The benefits of an effective information system is an improved understanding of the business functions, improved communications, better decision making, better problem analysis and better control.

Today, the successful planning cannot be conducted without appropriate software. The last three decades have occurred numerous innovations that have changed the way organizations carry out and control the planning and over time they are more and more adapted to the needs of users. There is still a need for a system that will help the top management in the implementation of the established business strategies and give support for effective decision making.

The effort to abandon traditional planning and embrace new trends in planning resulted in a new discipline called corporate performance management which is a set of management and analytic processes supported by technology. Along with the increasing complexity and turbulence in the business environment and the development of the information technology, these types of information systems are developed to support strategic decision mak12 Ibid., p. 60 
ing: commercially available conventional computer software to support strategic decision making, conventional computer software with general purpose and systems used for strategic planning, ssystems that are based on knowledge to support strategic management, integral - group software for strategic management, and strategic use of computer - information systems.

\section{REFERENCES}

[1] Berry, T. (2003), The book on business planning, Palo Alto Software Inc, Eugene, OR, USA.

[2] Bidgoli, H. (2004), The Internet Encyclopedia, Vol. 1, John Wiley \& Sons Inc, New York.

[3] Buble, M. (2000), Management, Ekonomsku fakultet Split, Split.

[4] Cavusgil, S.T., Knight G. and Riesenberger, J. R. (2008), International Business, Strategy, Management and the New Realities, Pearson Prentice Hall, New Jersey.
[5] Frolick, M.N. and Ariyachandra, T.R. (2006), "Business performance management: one truth", Information system management Journal, Vol. 23, No.1, pp. 41-48

[6] Geishecker, L. and Rayner, N. (2001), Corporate Performance Management: BI Collides with ERP, Gartner Inc., Stamford.

[7] http://www-01.ibm.com/software/analytics/cognos/planning/ (19.03.2014)

[8] Khosrow-Puor, M. (2006), Emerging Trends and Challenges in Information Technology Management, Idea Group Inc, Stratford.

[9] Oreščanin, D. (2007), Čemu zapravo služi Business Intelligence?, www.inteligencija.com. (20.03.2014)

[10] Rayner, N., Buytendijk, F. and Geishecker, L. (2002), The Processes That Drive CPM, Gartner Inc., Stamford.

[11] Шуклев, Б. и Дебарлиев, С. (2009), Деловно планирање, 4-то издание, Економски факултет Скопје. 